\title{
Characteristics of Patients with Psoriasis Treated with Apremilast in the Corrona Psoriasis Registry
}

\author{
Alice B. Gottlieb · Joseph F. Merola · Joshua Cirulli • Catherine C. Williams • \\ Gregory J. Linowski • Maria Paris · Heather J. Litman • \\ Ning Guo · Kelechi Emeanuru • Robert R. McLean • Angel Cronin • \\ Bruce Strober
}

Received: September 23, 2020 / Published online: January 21, 2021

(C) The Author(s) 2021

\section{ABSTRACT}

Introduction: Data on the characteristics of apremilast patients in real-world settings are limited. We assessed the demographics and disease characteristics of apremilast-treated patients in the Corrona Psoriasis Registry overall and by treatment history.

Methods: The Corrona Psoriasis Registry is a large, independent, prospective, observational registry of adult patients (age $\geq 18$ years) who

\author{
A. B. Gottlieb $(\bowtie)$ \\ Department of Dermatology, Mount Sinai Beth \\ Israel Hospital, Icahn School of Medicine at Mount \\ Sinai, New York, NY, USA \\ e-mail: alice.gottlieb@mountsinai.org \\ J. F. Merola \\ Brigham and Women's Hospital, Harvard Medical \\ School, Boston, MA, USA \\ J. Cirulli \\ Celgene Corporation, Summit, NJ, USA \\ C. C. Williams · G. J. Linowski · M. Paris \\ Amgen Inc., Thousand Oaks, CA, USA \\ H. J. Litman · N. Guo · K. Emeanuru . \\ R. R. McLean · A. Cronin \\ Corrona, LLC, Waltham, MA, USA \\ B. Strober \\ Yale University, New Haven, CT, USA \\ B. Strober \\ Central Connecticut Dermatology Research, \\ Cromwell, CT, USA
}

initiate an eligible systemic medication for treatment of psoriasis at or after enrollment (incident users) or within 12 months before enrollment (prevalent users). The current analyses included psoriasis patients enrolled in the Corrona Psoriasis Registry between April 1, 2015, and January 7, 2018. Patients were adults (age $\geq 18$ years) with psoriasis who were enrolled between April 1, 2015, and January 7, 2018 and initiated apremilast at the time of registry enrollment or a subsequent visit (incident users) or within the 12 months prior to registry enrollment (prevalent users). Patient characteristics were evaluated descriptively at the index date, defined as the enrollment date for prevalent users and the visit when apremilast was initiated for incident users.

Results: Among 660 patients who initiated apremilast at registry enrollment or a visit thereafter, psoriatic arthritis, hypertension, and hyperlipidemia were common. There were more systemic-experienced $(61.4 \%)$ versus systemicnaive $(38.6 \%)$ patients; $43.8 \%$ had prior biologic exposure. Most patients were not receiving concomitant systemic treatment (70.2\%); $27.4 \%$ were receiving concomitant biologic therapy. Most patients had mild or moderate disease (psoriasis-involved body surface area $\leq 10 \% \quad[76.0 \%]$, Investigator Global Assessment $\leq 3$ [88.3\%], Psoriasis Area and Severity Index $\leq 10 \quad[84.5 \%]) . \quad$ Dermatologist-reported psoriatic arthritis was present in $47.0 \%$ of patients; $33.9 \%$ of patients had a Psoriasis 
Epidemiology Screening Tool score of $\geq 3$, suggestive of psoriatic arthritis. Systemic-experienced apremilast patients had higher rates of obesity and comorbidities and experienced a greater impact on quality of life (mean Dermatology Life Quality Index, 7.3 vs. 6.5) versus systemic-naive patients.

Conclusion: In this real-world observational study of apremilast users in the Corrona Psoriasis Registry, most patients had less-severe disease and higher rates of prior exposure to biologic treatments compared with patients with moderate-to-severe psoriasis enrolled in phase 3 clinical studies.

Keywords: Apremilast; Corrona Psoriasis Registry; Psoriasis; Observational study; Realworld

\section{Key Summary Points}

Why carry out this study?

To determine the demographic and clinical characteristics of patients treated with apremilast in the Corrona Psoriasis Registry.

\section{What was learned from the study?}

In this observational study of apremilast users enrolled in the Corrona Psoriasis Registry, most had less-severe skin disease and greater biologic experience versus trials in patients with moderate-to-severe psoriasis. One-third of patients had a Psoriasis Epidemiology Screening Tool score indicating PsA, and many received concomitant biologics.

In real-world clinical practice, physicians prescribed apremilast to patients who had less-severe psoriasis compared with apremilast patients in the phase 3 ESTEEM studies, but apremilast patients in the Corrona Psoriasis Registry had psoriasis severity that was more comparable to patients in the phase 4 UNVEIL study.

\section{DIGITAL FEATURES}

This article is published with digital features, including a summary slide, to facilitate understanding of the article. To view digital features for this article go to https://doi.org/10.6084/ m9.figshare.13379888.

\section{INTRODUCTION}

Apremilast, an oral phosphodiesterase- 4 inhibitor, is approved for the treatment of adult patients with moderate-to-severe plaque psoriasis who are candidates for phototherapy or systemic therapy and patients with active psoriatic arthritis (PsA). In phase 3 clinical trials, apremilast demonstrated efficacy, a favorable tolerability profile, and improvements in pruritus and quality of life (QOL) versus placebo in patients with moderate-to-severe plaque psoriasis [1-3].

Limited data are available regarding the types of patients with psoriasis who are initiated on apremilast treatment in US dermatology care settings [4-7]. The Corrona Psoriasis Registry was launched in 2015, in collaboration with the National Psoriasis Foundation, to better characterize the epidemiology and natural history of psoriasis and the safety and effectiveness of systemic psoriasis treatments in real-world US patients [8]. To further understand the profile of psoriasis patients treated with apremilast in the United States, demographic, clinical, and treatment characteristics at enrollment or the time of apremilast initiation were evaluated among patients in the Corrona Psoriasis Registry who received apremilast. To elucidate the treatment patterns in the real-world use of apremilast, analyses were performed that compared apremilast users at the time of registry enrollment or apremilast initiation. We hypothesized that characteristics would vary according to psoriasis treatment history. 


\section{METHODS}

\section{Registry Design and Patient Population}

The Corrona Psoriasis Registry is a large, independent, prospective, observational registry of adult patients (age $\geq 18$ years) with a dermatologist's diagnosis of psoriasis who initiate an eligible systemic medication for treatment of psoriasis at or after enrollment (incident users) or within 12 months before enrollment (prevalent users) [8]. Eligible treatments approved by the US Food and Drug Administration for psoriasis as of the date of data analysis (January 7, 2018) were biologics (adalimumab, brodalumab, etanercept, guselkumab, infliximab, ixekizumab, secukinumab, and ustekinumab) and nonbiologic systemic agents (acitretin, apremilast, cyclosporine, and methotrexate). The target enrollment for patients initiating a nonbiologic systemic medication $(N=500)$ was met on June 20, 2016, and patients initiating nonbiologic systemic medications (e.g., apremilast) are no longer being enrolled. After June 20, 2016, the only patients receiving nonbiologics who were enrolled in the registry were those who switched from an eligible medication to a nonbiologic. At the time of data analysis (January 7,2018 ), the registry patients were recruited by 443 participating dermatologists from 193 private and academic practice sites in 43 US states and Canada.

\section{Data Collection}

The registry collects patient and physician data using questionnaires during routine dermatology office visits approximately every 6 months. All participating investigators were required to obtain full board approval to conduct research involving human subjects. Sponsor approval and approval for continuing review were obtained through a central institutional review board (IRB; IntegReview, Corrona-PSO-500). For academic investigative sites that did not receive a waiver to use the central IRB, full board approval was obtained from the respective governing IRBs, and approval documentation was submitted to the sponsor before initiating any study procedures. This study was performed in accordance with the Helsinki Declaration of 1964 and its later amendments. All registry patients were required to provide written informed consent before participating.

\section{Assessments}

Patient characteristics evaluated at visits included demographics (e.g., age, gender, race, ethnicity, health insurance type, employment status), lifestyle characteristics (e.g., body weight, body mass index), and comorbidities (current and previous). Patient disease and treatment profiles were characterized by assessing psoriasis duration and morphology, the diagnosis and duration of PsA, clinical assessments (psoriasis-involved body surface area [BSA]; Psoriasis Area and Severity Index [PASI, 0-72]; Investigator Global Assessment [IGA, 0-4]; Psoriasis Epidemiology Screening Tool [PEST, 0-5]), and prior and concomitant psoriasis treatments. Patient-reported outcome (PRO) measures included Dermatology Life Quality Index (DLQI, 0-30) and visual analog scales (VASs; 0-100 mm) for skin pain, fatigue, and pruritus.

\section{Statistical Analysis}

The current analyses represent a cross-sectional descriptive study that included psoriasis patients enrolled in the Corrona Psoriasis Registry between April 1, 2015, and January 7, 2018. Patient characteristics at the index date were evaluated in patients who initiated apremilast at the time of registry enrollment or a subsequent visit (incident users) or who initiated apremilast within the 12 months before registry enrollment (prevalent users). The index date was defined as the enrollment date for prevalent users and the visit when apremilast was initiated for incident users.

Descriptive statistics at index were calculated for categorical (no. [\%]) and continuous (mean [SD]) variables in the overall apremilast population, and by apremilast user type (incident or prevalent) and prior systemic experience (systemic-naive or systemic-experienced). Systemic- 
experienced patients were defined as those who had prior treatment with a biologic (adalimumab, brodalumab, guselkumab, etanercept, infliximab, ixekizumab, secukinumab, and ustekinumab) or nonbiologic (acitretin, apremilast, cyclosporine, and methotrexate) systemic therapy. Data were evaluated as observed; no methodology was used to impute missing values.

\section{RESULTS}

\section{Patient Demographics and Comorbidity Profile}

Among the 3902 patients enrolled in the Corrona Psoriasis Registry as of January 7, 2018, 660 apremilast-treated patients were included in descriptive analyses of demographic, clinical, and treatment characteristics, including 461 prevalent apremilast users and 199 incident apremilast users. There were also 255 systemicnaive and 405 systemic-experienced patients among the apremilast-treated patients.

Patient demographics and comorbidities at index are summarized in Table 1. Overall, mean (SD) age was 53.7 (14.1) years, half of the patients were female, and almost three-quarters were white. At index, most of the patients were overweight or obese, and the most common comorbidities were PsA, hypertension, and hyperlipidemia. The proportion of prevalent users was higher than that of incident users, and there were more systemic-experienced than systemic-naive patients. More than two-thirds of the patients had private health insurance, and half were employed full time.

Rates of common comorbidities were generally similar for incident and prevalent users; however, the proportion of obese patients was lower among prevalent than incident users, and prevalent users had lower rates of cancer and higher rates of cardiovascular disease and depression than incident users. Demographic characteristics were mostly similar for systemicnaive versus systemic-experienced patients; however, the proportion of obese patients was higher for systemic-experienced patients. Systemic-naive patients had lower rates of most comorbid diseases compared with systemic-experienced patients, except for cardiovascular disease, which was similar between groups.

\section{Patient Disease and Treatment Profile}

Among apremilast users in the Corrona Psoriasis Registry, the mean (SD) psoriasis duration was 14.3 (13.9) years; approximately one-third of patients had scalp psoriasis, and approximately one-third had a PEST score of $\geq 3$, suggestive of PsA (Table 1) $[9,10]$. Most patients had BSA $\leq 10 \%$, IGA $\leq 3$, and PASI $\leq 10$ (Fig. 1, Table 1 ). Many patients had previously been treated with systemic or biologic therapy. The majority were receiving apremilast as monotherapy or concomitantly with topical therapy, and most patients were not receiving concomitant systemic treatment; $27.4 \%$ of patients had concomitant treatment with a biologic therapy. The use of apremilast in combination with a biologic was more prevalent in systemic-experienced versus systemic-naive patients, and in prevalent versus incident apremilast users.

The mean duration of psoriasis was similar for incident and prevalent users and shorter for systemic-naive versus systemic-experienced patients (Table 1). The proportions of patients with scalp psoriasis were similar among incident versus prevalent users and systemic-naive versus systemic-experienced patients. The proportions of patients with a PEST score of $\geq 3$ were similar between incident and prevalent users; however, a PEST score of $\geq 3$ was reported in a lower proportion of systemic-naive versus systemic-experienced patients. In general, prevalent users and systemic-naive patients had less-severe disease at the index date (i.e., a lower mean BSA, IGA category, and mean PASI score) than incident users and systemic-experienced patients, respectively, and the proportion of patients with severe to very severe psoriasis (i.e., BSA $>10 \%$ ) was lower in prevalent and systemic-naive versus incident and systemic-experienced patients (Fig. 1). The proportion of patients with prior use of systemic treatments was similar in incident versus prevalent users, and the proportion of patients with prior biologic use was higher in incident versus 
Table 1 Patient demographics, disease characteristics, and treatment profile at index date

\begin{tabular}{|c|c|c|c|c|c|}
\hline Characteristic & $\begin{array}{l}\text { Overall apremilast } \\
\text { population } \\
N=660\end{array}$ & $\begin{array}{l}\text { Incident } \\
\text { users } \\
n=199\end{array}$ & $\begin{array}{l}\text { Prevalent } \\
\text { users } \\
n=461\end{array}$ & $\begin{array}{l}\text { Systemic- } \\
\text { naive } \\
n=255\end{array}$ & $\begin{array}{l}\text { Systemic- } \\
\text { experienced } \\
\mathrm{n}=405\end{array}$ \\
\hline Age, mean (SD), years & $53.7(14.1)$ & $53.0(13.9)$ & $54.0(14.2)$ & $53.3(15.0)$ & $53.9(13.5)$ \\
\hline Female, no. (\%) & $332(50.3)$ & $99(49.7)$ & $233(50.5)$ & $125(49.0)$ & $207(51.1)$ \\
\hline \multicolumn{6}{|l|}{ Race, no. (\%) } \\
\hline White & $477(72.3)$ & $157(78.9)$ & $320(69.4)$ & $175(68.6)$ & $302(74.6)$ \\
\hline African American & $17(2.6)$ & $11(5.5)$ & $6(1.3)$ & $6(2.4)$ & $11(2.7)$ \\
\hline Asian & $113(17.1)$ & $18(9.0)$ & $95(20.6)$ & $50(19.6)$ & $63(15.6)$ \\
\hline Other & $53(8.0)$ & $13(6.5)$ & $40(8.7)$ & $24(9.4)$ & $29(7.2)$ \\
\hline Body mass index, mean $(\mathrm{SD}), \mathrm{kg} / \mathrm{m}^{2}$ & $30.2(7.3)$ & $31.0(8.1)$ & $29.8(6.9)$ & $29.2(6.7)$ & $30.8(7.6)$ \\
\hline \multicolumn{6}{|l|}{ Body mass index category, no. (\%) } \\
\hline Underweight $/$ normal $\left(<25 \mathrm{~kg} / \mathrm{m}^{2}\right)$ & $162(24.5)$ & $47(23.6)$ & $115(24.9)$ & $77(30.2)$ & $85(21.0)$ \\
\hline Overweight $\left(\geq 25\right.$ to $<30 \mathrm{~kg} / \mathrm{m}^{2}$ ) & $218(33.0)$ & $60(30.2)$ & $158(34.3)$ & $85(33.3)$ & $133(32.8)$ \\
\hline Obese $\left(\geq 30 \mathrm{~kg} / \mathrm{m}^{2}\right)$ & $280(42.4)$ & $92(46.2)$ & $188(40.8)$ & $93(36.5)$ & $187(46.2)$ \\
\hline Body weight, mean (SD), kg & $86.5(23.2)$ & $89.2(23.2)$ & $85.3(23.1)$ & $83.0(20.9)$ & $88.6(24.4)$ \\
\hline \multicolumn{6}{|l|}{ Health insurance type, no. (\%) } \\
\hline Private & $446(68.0)$ & $144(72.4)$ & $302(66.1)$ & $169(66.8)$ & $277(68.7)$ \\
\hline Medicare & $123(18.8)$ & $31(15.6)$ & $92(20.1)$ & $49(19.4)$ & $74(18.4)$ \\
\hline Medicaid & $73(11.1)$ & $19(9.5)$ & $54(11.8)$ & $31(12.3)$ & $42(10.4)$ \\
\hline No insurance & $14(2.1)$ & $5(2.5)$ & $9(2.0)$ & $4(1.6)$ & $10(2.5)$ \\
\hline Full-time employment, no. (\%) & $332(50.4)$ & $105(52.8)$ & $227(49.3)$ & $126(49.4)$ & $206(51.0)$ \\
\hline \multicolumn{6}{|l|}{$\begin{array}{l}\text { History of comorbidities }{ }^{a} \text { in } \geq 5 \% \text {, } \\
\text { no. }(\%)\end{array}$} \\
\hline Hypertension & $304(46.1)$ & $87(43.7)$ & $217(47.1)$ & $105(41.2)$ & $199(49.1)$ \\
\hline Hyperlipidemia & $213(32.3)$ & $60(30.2)$ & $153(33.2)$ & $73(28.6)$ & $140(34.6)$ \\
\hline Depression & $113(17.1)$ & $27(13.6)$ & $86(18.7)$ & $34(13.3)$ & $79(19.5)$ \\
\hline Cardiovascular disease & $109(16.5)$ & $24(12.1)$ & $85(18.4)$ & $41(16.1)$ & $68(16.8)$ \\
\hline Anxiety & $108(16.4)$ & $31(15.6)$ & $77(16.7)$ & $35(13.7)$ & $73(18.0)$ \\
\hline Diabetes mellitus & $107(16.2)$ & $32(16.1)$ & $75(16.3)$ & $37(14.5)$ & $70(17.3)$ \\
\hline IBD/other GI disorders ${ }^{\mathrm{b}}$ & $95(14.4)$ & $29(14.6)$ & $66(14.3)$ & $35(13.7)$ & $60(14.8)$ \\
\hline Cancer $^{c}$ & $92(13.9)$ & $35(17.6)$ & $57(12.4)$ & $30(11.8)$ & $62(15.3)$ \\
\hline Serious infection & $53(8.0)$ & $19(9.5)$ & $34(7.4)$ & $13(5.1)$ & $40(9.9)$ \\
\hline PsA & $310(47.0)$ & $96(48.2)$ & $214(46.4)$ & $83(32.5)$ & $227(56.0)$ \\
\hline PsA duration, mean $(\mathrm{SD})$, years & $9.7(10.6)$ & $10.0(11.0)$ & $9.5(10.4)$ & $6.1(6.9)$ & $11.0(11.3)$ \\
\hline Psoriasis duration, mean (SD), years & $14.3(13.9)$ & $13.9(13.4)$ & $14.5(14.1)$ & $11.9(13.4)$ & $15.8(14.0)$ \\
\hline \multicolumn{6}{|l|}{ Psoriasis morphology, no. (\%) } \\
\hline Plaque & $632(95.8)$ & $193(97.0)$ & $439(95.2)$ & $244(95.7)$ & $388(95.8)$ \\
\hline Guttate & $23(3.5)$ & $11(5.5)$ & $12(2.6)$ & $8(3.1)$ & $15(3.7)$ \\
\hline Erythrodermic & $10(1.5)$ & $4(2.0)$ & $6(1.3)$ & $0(0.0)$ & $10(2.5)$ \\
\hline Pustular (localized) & $5(0.8)$ & $2(1.0)$ & $6(1.3)$ & $1(0.4)$ & $7(1.7)$ \\
\hline Pustular (generalized) & $8(1.2)$ & $1(0.5)$ & $4(0.9)$ & $0(0.0)$ & $5(1.2)$ \\
\hline Inverse/intertriginous & $35(5.3)$ & $11(5.5)$ & $24(5.2)$ & $14(5.5)$ & $21(5.2)$ \\
\hline Scalp & $210(31.8)$ & $69(34.7)$ & $141(30.6)$ & $77(30.2)$ & $133(32.8)$ \\
\hline Nail & $74(11.2)$ & $22(11.1)$ & $52(11.3)$ & $16(6.3)$ & $58(14.3)$ \\
\hline Palmoplantar & $73(11.1)$ & $22(11.1)$ & $51(11.1)$ & $24(9.4)$ & $49(12.1)$ \\
\hline $\operatorname{PEST}(0-5) \geq 3$, no. (\%) & $222(33.9)$ & $62(31.5)$ & $160(34.9)$ & $50(19.8)$ & $172(42.7)$ \\
\hline
\end{tabular}


Table 1 continued

\begin{tabular}{|c|c|c|c|c|c|}
\hline Characteristic & $\begin{array}{l}\text { Overall apremilast } \\
\text { population } N=660\end{array}$ & $\begin{array}{l}\text { Incident } \\
\text { users } n=199\end{array}$ & $\begin{array}{l}\text { Prevalent } \\
\text { users } n=461\end{array}$ & $\begin{array}{l}\text { Systemic- } \\
\text { naiven } n=255\end{array}$ & $\begin{array}{l}\text { Systemic- } \\
\text { experiencedn }=405\end{array}$ \\
\hline BSA, mean $(S D)$ & $10.3(14.9)$ & $12.0(15.7)$ & $9.5(14.5)$ & $7.7(10.6)$ & $11.9(16.9)$ \\
\hline PASI (0-72), mean (SD) & $5.7(6.6)$ & $6.5(7.0)$ & $5.4(6.5)$ & $4.8(6.0)$ & $6.3(7.0)$ \\
\hline PASI > 10, no. $(\%)$ & $102(15.5)$ & $31(15.6)$ & $71(15.4)$ & $26(10.2)$ & $76(18.8)$ \\
\hline \multicolumn{6}{|l|}{ IGA category, no. (\%) } \\
\hline 0 (clear) & $52(7.9)$ & $13(6.5)$ & $39(8.5)$ & $18(7.1)$ & $34(8.4)$ \\
\hline 1 (almost clear) & $76(11.5)$ & $16(8.0)$ & $60(13.0)$ & $37(14.5)$ & $39(9.6)$ \\
\hline 2 (mild) & $176(26.7)$ & $40(20.1)$ & $136(29.5)$ & $79(31.0)$ & $97(24.0)$ \\
\hline 3 (moderate) & $279(42.3)$ & $101(50.8)$ & $178(38.6)$ & $97(38.0)$ & $182(44.9)$ \\
\hline 4 (severe) & $77(11.7)$ & $29(14.6)$ & $48(10.4)$ & $24(9.4)$ & $53(13.1)$ \\
\hline DLQI (0-30), mean (SD) & $7.0(6.0)$ & $7.2(6.1)$ & $6.9(5.9)$ & $6.5(5.6)$ & $7.3(6.2)$ \\
\hline \multicolumn{6}{|l|}{ Prior medication use, no. (\%) } \\
\hline$\geq 1$ Systemic & $405(61.4)$ & $125(62.8)$ & $280(60.7)$ & 0 & $405(100.0)$ \\
\hline$\geq 1$ Biologic & $289(43.8)$ & $97(48.7)$ & $192(41.6)$ & 0 & $289(71.4)$ \\
\hline \multicolumn{6}{|l|}{ Concomitant systemic therapy, no. (\%) } \\
\hline $\begin{array}{l}\text { Apremilast monotherapy (i.e., without } \\
\text { concomitant systemic therapy) }\end{array}$ & $463(70.2)$ & $168(84.4)$ & $295(64.0)$ & $238(93.3)$ & $213(52.6)$ \\
\hline Apremilast + any biologic & $181(27.4)$ & $24(12.1)$ & $157(34.1)$ & $16(6.3)$ & $165(40.7)$ \\
\hline Apremilast + biologic (TNF inhibitor) & $67(10.2)$ & $15(7.5)$ & $52(11.3)$ & $7(2.7)$ & $60(14.8)$ \\
\hline Apremilast + biologic (other) & $114(17.3)$ & $9(4.5)$ & $105(22.8)$ & $9(3.5)$ & $105(25.9)$ \\
\hline Apremilast + nonbiologic systemic & $16(2.4)$ & $7(3.5)$ & $9(2.0)$ & 0 & $16(4.0)$ \\
\hline Concomitant topical, no. (\%) & $460(69.7)$ & $111(55.8)$ & $349(75.7)$ & $188(73.7)$ & $272(67.2)$ \\
\hline Concomitant phototherapy, no. (\%) & $68(10.3)$ & $7(3.5)$ & $61(13.2)$ & $41(16.1)$ & $27(6.7)$ \\
\hline \multicolumn{6}{|l|}{$\begin{array}{l}\text { Patient-reported outcome based on visual } \\
\text { analog scald }^{\mathrm{d}}(0-100 \mathrm{~mm}) \text {, mean }(\mathrm{SD})\end{array}$} \\
\hline Skin pain & $25.0(29.3)$ & $30.1(31.1)$ & $22.8(28.2)$ & $21.6(27.6)$ & $27.1(30.1)$ \\
\hline Fatigue & $35.3(29.8)$ & $37.5(29.2)$ & $34.3(30.0)$ & $32.4(29.2)$ & $37.1(30.0)$ \\
\hline Pruritus & $40.9(32.2)$ & $45.8(33.4)$ & $38.8(31.4)$ & $38.4(30.9)$ & $42.5(32.9)$ \\
\hline
\end{tabular}

Number of patients with data available varied with the characteristic considered

Index date is defined as enrollment date for prevalent users and the visit when apremilast was initiated for incident users

$B S A$ psoriasis-involved body surface area, DLQI Dermatology Life Quality Index, GI gastrointestinal, $I B D$ inflammatory bowel disease, IGA Investigator's Global Assessment, PASI Psoriasis Area and Severity Index, PEST Psoriasis Epidemiology Screening Tool, PsA psoriatic arthritis, $S D$ standard deviation, $T N F$ tumor necrosis factor

a Includes comorbidities at or prior to the index visit

b Includes IBD/other GI disorders, ulcerative colitis, or Crohn's disease

c Excludes non-melanoma skin cancer

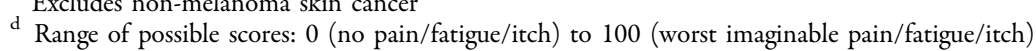

prevalent users (Table 1). Apremilast monotherapy was more frequent in incident versus prevalent users and in systemic-naive versus systemic-experienced patients. Concomitant use of topical treatments was less frequent in incident versus prevalent users and more frequent in systemic-naive versus systemic-experienced patients.

\section{PRO Measures}

Approximately $25 \%$ of patients reported a very large or extremely large impact of psoriasis on QOL at index in the overall apremilast population. The proportion of patients who reported a very large or extremely large impact of psoriasis on QOL was similar for incident and prevalent 


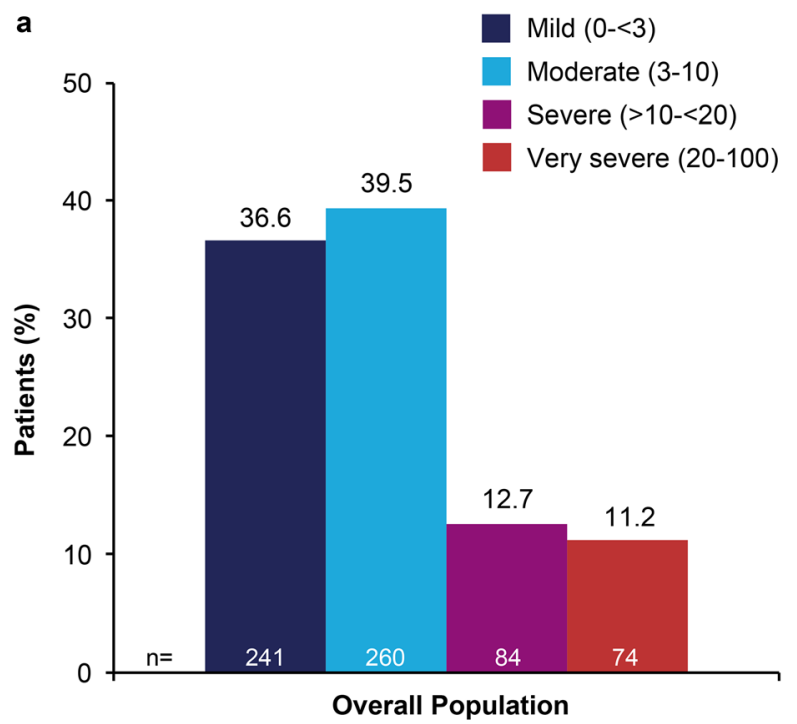

b

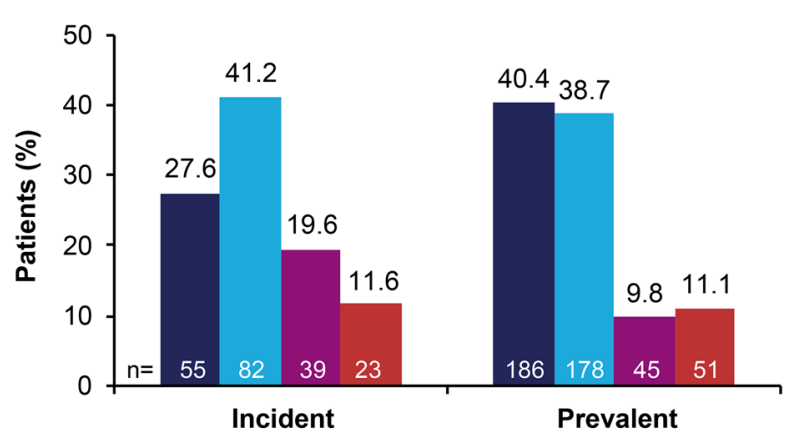

C

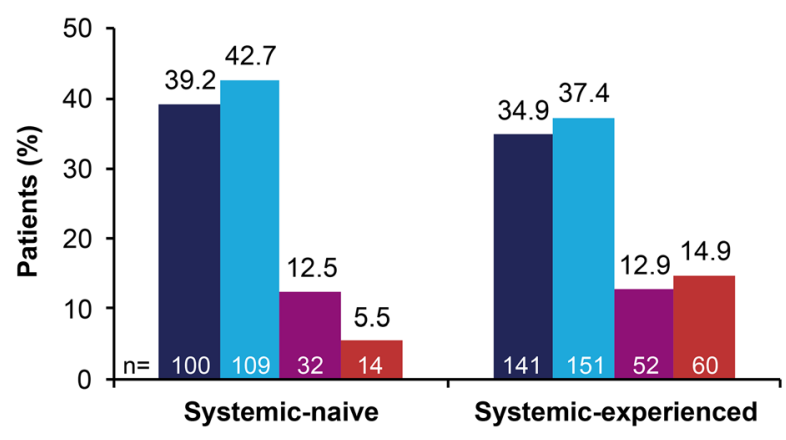

Fig. 1 BSA in a the overall apremilast population, b incident versus prevalent users, c systemic-naive versus systemic-experienced users. Incident $=$ initiated apremilast treatment at or after enrollment; prevalent $=$ initiated apremilast treatment within 12 months before enrollment

users and numerically lower in systemic-naive versus systemic-experienced patients (Fig. 2).

Patient-reported skin pain and pruritus VAS scores were higher in incident versus prevalent
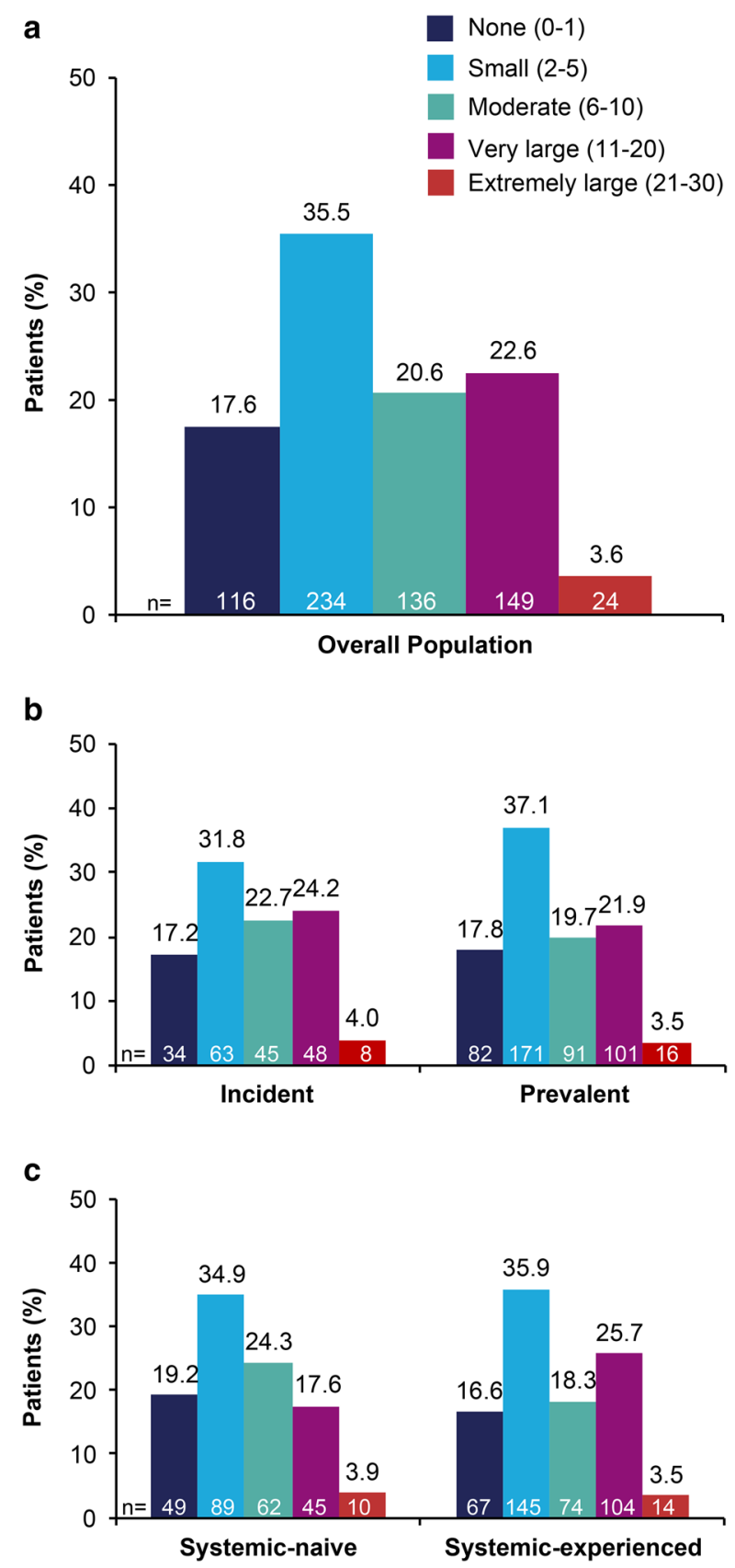

Fig. 2 DLQI in a the overall apremilast population, b incident versus prevalent users, c systemic-naive versus systemic-experienced users. Incident $=$ initiated treatment at or after enrollment; prevalent $=$ initiated treatment within 12 months before enrollment

users and generally similar in systemic-naive and systemic-experienced patients (Table 1). Fatigue VAS scores were generally similar in the overall apremilast population, incident and 
prevalent users, and systemic-naive and systemic-experienced patients (Table 1).

\section{DISCUSSION}

This report of real-world use of apremilast among patients in the Corrona Psoriasis Registry provides insights into the demographic, disease, and treatment characteristics of apremilast patients in clinical practice settings in the United States. Apremilast users in the Corrona Psoriasis Registry had mean BSA and PASI scores at the index date $(10.3 \%$ and 5.7 , respectively) that were more similar to patients with moderate plaque psoriasis enrolled in the UNVEIL study (7.2\% and 8.1)-which required BSA $5-10 \%$ for enrollment [11] -than to patients with moderate-to-severe psoriasis in the pooled ESTEEM studies (25.2\% and 19.1). The higher baseline PASI scores in the phase 3 ESTEEM studies are a reflection of the inclusion criteria (PASI score $\geq 12$ ), whereas in the realworld Corrona Psoriasis Registry, physicians had the option to initiate apremilast at their discretion based on their clinical experience. PROs, including DLQI and pruritus VAS scores, were lower at index for apremilast users in the Corrona Psoriasis Registry (DLQI: 7.0; pruritus VAS: $40.9 \mathrm{~mm}$ ) compared with baseline scores for patients in the pooled ESTEEM studies (DLQI: 12.4 with placebo and 12.7 with apremilast; pruritus VAS: $65.1 \mathrm{~mm}$ with placebo and $66.6 \mathrm{~mm}$ with apremilast) and in the overall study population of UNVEIL (DLQI: 11.0; pruritus VAS: $56.6 \mathrm{~mm}$ ) [11]. Approximately one-third of apremilast users in the Corrona Psoriasis Registry had scalp psoriasis, which is considerably lower than the proportion of patients with scalp psoriasis (Scalp Physician Global Assessment $\geq 1$ ) in the pooled ESTEEM (93.2\%) and UNVEIL (75.6\%) studies.

Apremilast-treated patients in the Corrona Psoriasis Registry had a high rate of prior exposure to biologic therapy $(43.8 \%)$, in contrast with patients in the pooled ESTEEM studies $(30.1 \%)$ and apremilast-treated patients in a recent health-claims analysis of a large healthcare plan (18.1\%) [12], demonstrating that some apremilast users in the Corrona Psoriasis
Registry had more severe disease before switching to apremilast. Nearly half of the apremilast users in the Corrona Psoriasis Registry had comorbid PsA, which is higher than the proportion of overall users with concurrent PsA in the Corrona Psoriasis Registry (40\%) [8], the pooled ESTEEM studies (20.0\%), and the UNVEIL study (14.5\%); thus, apremilast users may have had a greater psoriatic disease burden than patients in the general Corrona Psoriasis Registry population. Apremilast users in the Corrona Psoriasis Registry had numerically higher rates of hypertension, hyperlipidemia, and diabetes than the overall Corrona Psoriasis Registry population [8] and patients with moderate psoriasis treated with apremilast in a realworld, prospective, 6-month chart review [6]. It is possible that some patients in the Corrona Psoriasis Registry switched from a biologic to apremilast due to safety concerns, a common patient-reported reason for discontinuing biologics [13].

As hypothesized, we found some key differences between the characteristics of apremilast users who had received prior systemic treatment versus those who were systemic-naive. Systemic-experienced patients had higher comorbidity burden, including higher rates of PsA and PEST score $\geq 3$, more severe psoriasis, and a greater impact of psoriasis on QOL compared with systemic-naive patients. The use of apremilast in combination with other systemic treatments was more common among systemicexperienced versus systemic-naive patients, in agreement with a recent analysis of the Corrona Psoriasis Registry, which found that the majority of psoriasis patients receiving systemic treatments in combination had prior experience with systemic agents for psoriasis [14]. More than one-quarter of patients received apremilast along with a biologic therapy. Higher rates of concomitant biologic use were observed among prevalent versus incident users and among systemic-experienced versus systemic-naive patients. Taken together, these findings suggest that some systemic-experienced patients in the Corrona Psoriasis Registry may have received apremilast in combination with other systemic treatments, including biologic therapy, to help manage more severe psoriasis. 
Findings of this observational study are limited to physicians and patients who voluntarily enrolled in the Corrona Psoriasis Registry in the United States, and may not be generalizable to all psoriasis patients or psoriasis patients in other regions.

\section{CONCLUSIONS}

In this real-world observational study of patients treated with apremilast in the Corrona Psoriasis Registry, most patients who received apremilast had less-severe disease than patients in phase 3 clinical trials, which enrolled patients with moderate-to-severe psoriasis. However, apremilast users in the Corrona Psoriasis Registry had higher rates of prior exposure to biologic treatments compared with patients in phase 3 clinical trials of apremilast. Systemicexperienced apremilast patients had a higher comorbidity burden, more severe psoriasis, and experienced a greater impact of psoriasis on QOL compared with systemic-naive patients. Use of apremilast in combination with a biologic therapy was more common among prevalent versus incident users and in systemicexperienced versus systemic-naive patients.

\section{ACKNOWLEDGEMENTS}

We thank the participants of the study.

Funding. This study was sponsored by Corrona, LLC and the analysis was funded by Celgene Corporation. Amgen acquired the worldwide rights to Otezla ${ }^{\circledR}$ (apremilast) on November 21, 2019. Amgen funded the journal's rapid service fee.

Medical Writing and/or Editorial Assistance. The authors received editorial support in the preparation of this report from Amy Shaberman, PhD, of Peloton Advantage, LLC, an OPEN Health company, Parsippany, NJ, USA, sponsored by Celgene Corporation, Summit, NJ, USA and Amgen Inc., Thousand Oaks, CA, USA. The authors, however, directed and are fully responsible for all content and editorial decisions for this report.

Authorship. All named authors meet the International Committee of Medical Journal Editors (ICMJE) criteria for authorship of this article, take responsibility for the integrity of the work as a whole, and have given their approval for this version to be published.

Author Contributions. All authors contributed to the interpretation of the results.

Disclosures. Dr. Gottlieb has received honoraria as an advisory board member and consultant for Avotres Therapeutics, Beiersdorf, Boehringer Ingelheim, Bristol-Myers Squibb, Eli Lilly, Incyte, Janssen, LEO Pharma, Novartis, Sun Pharmaceutical Industries, UCB, and Xbiotech (only stock options which she has not used), and has received research/educational grants from Boehringer Ingelheim, Incyte, Janssen, Novartis, Sun Pharmaceuticals, UCB, and Xbiotech. Dr. Merola is a consultant and/or investigator for AbbVie, Arena, Avotres, Biogen, Bristol-Myers Squibb, Celgene Corporation, Dermavant, Eli Lilly and Company, EMD Serono, Janssen, LEO Pharma, Merck, Novartis, Pfizer, Regeneron, Sanofi, Sun Pharma, and UCB. Dr. Cirulli was an employee of Celgene Corporation at the time of the analysis and is currently an employee of Cara Therapeutics, Inc. Ms. Williams, Mr. Linowski, and Dr. Paris are employees of Amgen Inc. Dr. Litman, Ms. Guo, Ms. Emeanuru, Dr. McLean, and Ms. Cronin are employees of Corrona. Dr. Strober has served as a consultant and advisory board member for AbbVie, Almirall, Amgen Inc., Arena, Aristea, Boehringer Ingelheim, BristolMyers Squibb, Celgene Corporation, Dermavant, Dermira, Eli Lilly and Company, GlaxoSmithKline, Janssen, Kyowa Hakko Kirin, Leo Pharma, Meiji Seika Pharma, Novartis, Ortho Dermatologics, Pfizer Inc., Regeneron, Sanofi-Genzyme, Sun Pharma, and UCB; has served as an investigator for AbbVie, Corrona Psoriasis Registry, Dermavant, and Dermira; has served as a speaker for AbbVie, Amgen Inc., Eli Lilly and Company, Janssen, and Ortho Dermatologics; and is the Scientific Co-Director for the Corrona Psoriasis Registry. 
Corrona has been supported through contracted subscriptions in the last 2 years by AbbVie, Amgen Inc., Boehringer Ingelheim, Bristol-Myers Squibb, Celgene Corporation, Eli Lilly and Company, Genentech, Gilead, Janssen, Merck, Novartis, Ortho Dermatologics, Pfizer Inc., Regeneron, Sanofi-Genzyme, and Sun Pharma.

Compliance with Ethics Guidelines. All participating investigators were required to obtain full board approval to conduct research involving human subjects. Sponsor approval and continuing review approval was obtained through a central institutional review board (IRB; IntegReview, Corrona-PSO-500). For academic investigative sites that did not receive a waiver to use the central IRB, full board approval was obtained from the respective governing IRBs, and approval documentation was submitted to the sponsor before initiating any study procedures. This study was performed in accordance with the Helsinki Declaration of 1964 and its later amendments. All registry patients were required to provide written informed consent before participating in the registry.

Data Availability. The Corrona dataset is based on a large US multicenter study adhering to a number of institutional review boards, with complex logistics. Patients did not provide their consent for raw data sharing during the data collection for this purpose, and the Corrona data sharing policies do not permit raw data sharing for this purpose. An aggregated limited dataset from the current analyses is available to qualified investigators with an approved protocol. Data requests may be sent to Corrona, represented by Dr. Jeffrey D. Greenberg MD MPH, NYU School of Medicine, New York, NY, e-mail jgreenberg@corrona.org.

Open Access. This article is licensed under a Creative Commons Attribution-NonCommercial 4.0 International License, which permits any non-commercial use, sharing, adaptation, distribution and reproduction in any medium or format, as long as you give appropriate credit to the original author(s) and the source, provide a link to the Creative Commons licence, and indicate if changes were made. The images or other third party material in this article are included in the article's Creative Commons licence, unless indicated otherwise in a credit line to the material. If material is not included in the article's Creative Commons licence and your intended use is not permitted by statutory regulation or exceeds the permitted use, you will need to obtain permission directly from the copyright holder. To view a copy of this licence, visit http://creativecommons.org/licenses/by$\mathrm{nc} / 4.0 /$.

\section{REFERENCES}

1. Papp K, Reich K, Leonardi CL, Kircik L, Chimenti S, Langley RG, et al. Apremilast, an oral phosphodiesterase 4 (PDE4) inhibitor, in patients with moderate to severe plaque psoriasis: results of a phase III, randomized, controlled trial (Efficacy and Safety Trial Evaluating the Effects of Apremilast in Psoriasis [ESTEEM 1]). J Am Acad Dermatol. 2015;73: 37-49.

2. Paul C, Cather J, Gooderham M, Poulin Y, Mrowietz U, Ferrandiz C, et al. Efficacy and safety of apremilast, an oral phosphodiesterase 4 inhibitor, in patients with moderate to severe plaque psoriasis over 52 weeks: a phase III, randomized, controlled trial (ESTEEM 2). Br J Dermatol. 2015;173:1387-99.

3. Reich K, Gooderham M, Green L, Bewley A, Zhang $Z$, Khanskaya I, et al. The efficacy and safety of apremilast, etanercept, and placebo, in patients with moderate to severe plaque psoriasis: 52-week results from a phase $3 \mathrm{~b}$, randomized, placebo-controlled trial (LIBERATE). J Eur Acad Dermatol Venereol. 2017;31:507-17.

4. Papadavid E, Rompoti N, Theodoropoulos K, Kokkalis G, Rigopoulos D. Real-world data on the efficacy and safety of apremilast in patients with moderate-to-severe plaque psoriasis. J Eur Acad Dermatol Venereol. 2018;23:1173-1179.

5. Armstrong A, Levi E. Real-world clinical experience with apremilast in a large US retrospective cohort study of patients with moderate to severe plaque psoriasis. J Drugs Dermatol. 2017;16:1240-5.

6. Knuckles MLF, Levi E, Soung J. Treating moderate plaque psoriasis: prospective 6-month chart review of patients treated with apremilast. J Dermatol Treat. 2019;30:430-4. 
7. Lee EB, Amin M, Egeberg A, Wu JJ. Adverse events associated with apremilast use and withdrawal for psoriasis in a real-world setting. J Eur Acad Dermatol Venereol. 2018;32:e393-4.

8. Strober B, Karki C, Mason M, Guo N, Holmgren SH, Greenberg JD, et al. Characterization of disease burden, comorbidities, and treatment use in a large, US-based cohort: results from the Corrona Psoriasis Registry. J Am Acad Dermatol. 2018;78:323-32.

9. Ibrahim $\mathrm{GH}$, Buch $\mathrm{MH}$, Lawson $\mathrm{C}$, Waxman R, Helliwell PS. Evaluation of an existing screening tool for psoriatic arthritis in people with psoriasis and the development of a new instrument: the Psoriasis Epidemiology Screening Tool (PEST) questionnaire. Clin Exp Rheumatol. 2009;27: 469-74.

10. Mease PJ, Palmer JB, Hur P, Strober BE, Lebwohl M, Karki C, et al. Utilization of the validated Psoriasis Epidemiology Screening Tool to identify signs and symptoms of psoriatic arthritis among those with psoriasis: a cross-sectional analysis from the USbased Corrona Psoriasis Registry. J Eur Acad Dermatol Venereol. 2019;33:886-92.
11. Strober B, Bagel J, Lebwohl M, Stein Gold L, Jackson JM, Chen R, et al. Efficacy and safety of apremilast in patients with moderate plaque psoriasis with lower BSA: week 16 results from the UNVEIL study. J Drugs Dermatol. 2017;16:801-8.

12. Snow K, Ung B, Pelletier C, Edwards A, Edmonds S, Mehta R, et al. Patient characteristics and treatment patterns of psoriasis (PsO) and psoriatic arthritis (PsA) patients within a health plan [poster]. Presented at: AMCP Managed Care and Specialty Pharmacy Annual Meeting; April 23-26, 2018; Boston, MA.

13. Lebwohl MG, Bachelez H, Barker J, Girolomoni G, Kavanaugh A, Langley RG, et al. Patient perspectives in the management of psoriasis: results from the population-based Multinational Assessment of Psoriasis and Psoriatic Arthritis Survey. J Am Acad Dermatol. 2014;70:871-81.

14. Bonomo L, Abittan BJ, Hashim PW, Karki C, Mason M, Lebwohl M. Combination use of systemic therapies in psoriasis: baseline characteristics from the Corrona Psoriasis Registry. J Drugs Dermatol. 2019;18:731-40. 